Artigo

\title{
Correspondência identitária e engajamento militante
}

\author{
Identitary correspondence and militant engagement \\ Carlos José Naujorks* \\ Marcelo Kunrath Silva**
}

\begin{abstract}
Resumo: O artigo analisa a relação entre identidade individual e engajamento tendo como foco de discussão os processos psicossociais que dispõem e sustentam o engajamento. Parte-se do argumento que a identidade constitui um processo de produção do reconhecimento que o sujeito elabora sobre si e os outros, individual e coletivamente. No âmbito individual, esse processo envolve três dimensões identitárias: a dimensão pessoal, a dimensão social e a dimensão coletiva. Alinhandose ao desenvolvimento atual no campo das teorias da identidade que problematizam a relação entre essas diferentes dimensões identitárias, o presente trabalho argumenta que a produção e manutenção da identidade militante acontece por um processo de correspondência identitária entre as dimensões pessoal, social e coletiva da identidade individual.
\end{abstract}

Palavras-chave: Identidade. Engajamento. Movimentos sociais

\begin{abstract}
The paper analyses the relation between individual identity and engagement focusing the discussion on the psychosocial processes that are available and support the engagement. The argument is that the identity is an acknowledgement production process that the subject elaborates about himself and others, individually and collectively. In an individual scope, this process involves three identity dimensions: the personal, the social, and the collective dimension. Attuned to the present development of the identity theory which problematize the relation among these different identity dimensions, the present work argues that the militant identity production happens by an identity correspondence process among personal, social and collective dimensions of individual identity.
\end{abstract}

Keywords: Identity. Commitment. Social movements

\footnotetext{
*Doutor em Sociologia pela Universidade Federal do Rio Grande do Sul (Ufrgs, Porto Alegre, RS, Brasil) e professor do Departamento de Psicologia da Universidade Federal de Santa Catarina em Florianópolis, SC, Brasil<carlos.naujorks@ufsc.br>.

**Doutor em Sociologia pela Ufrgs, onde é professor no Departamento de Sociologia e nos PPGs de Sociologia e de Desenvolvimento Rural<mksilva@ufrgs.br>.
} 


\section{Introdução}

O engajamento militante tem sido um tema de destaque nos estudos sobre os movimentos sociais nas últimas duas décadas (Sawicki e Siméant, 2011). No Brasil, no conjunto dos estudos dedicados aos movimentos sociais, os temas engajamento e militância têm estado significativamente presente. ${ }^{1}$ Atualmente evidenciam-se pelo menos duas grandes perspectivas de análise sobre o tema: a primeira enfatiza as retribuições associadas aos processos de participação e engajamento (Gaxie, 2005); a segunda, a importância para o engajamento das relações sociais, disposições e carreiras pessoais (Fillieule, 2001). Muito embora não excludentes, essas perspectivas se desenvolveram por tradições teóricas diferentes, enfocando dimensões distintas do processo de engajamento: enquanto a primeira enfatiza a centralidade de condições, mecanismos e processos de interpretação e atribuição de sentido ao engajamento a partir das retribuições, a segunda salienta a importância de condições, mecanismos e processos relacionais e disposicionais que sustentam o engajamento. Ambas, no entanto, incorporam uma perspectiva relacional do engajamento, que destaca fortemente a "análise das interações entre indivíduos e entre indivíduos e contextos de ação" (Sawicki e Siméant, 2011).

Tendo por referência os argumentos destas duas perspectivas, considerase que os estudos sobre engajamento militante devem contemplar pelo menos três dimensões inter-relacionadas: 1) a dimensão estrutural, que envolve a trajetória e o contexto sociocultural dos agentes; 2) a dimensão relacional, que envolve os processos de interação; e, por fim, 3) a dimensão interpretativa, que envolve os sentidos atribuídos pelos indivíduos ao contexto social, à ação coletiva e ao engajamento. O engajamento relaciona-se, assim, com as disposições socioculturais, com as interações sociais realizadas pelos indivíduos ao longo do tempo e pelos sentidos atribuídos pelo indivíduo à participação (Passy, 1998).

Enquanto ação realizada pelo indivíduo, o engajamento é, por excelência, uma ação que enlaça esse indivíduo a determinados grupos sociais e ao contexto em que está inserido. A compreensão dos processos individuais relacionados com o engajamento constitui, dessa forma, um aspecto central desse campo de investigação. A identidade constitui um desses processos.

\footnotetext{
${ }^{1}$ De um conjunto bastante significativo de coletâneas sobre movimentos sociais publicadas no Brasil nas últimas décadas, algumas foram dedicadas de forma específica ou em parte à temática da militância. Ver, por exemplo, Sociologias (2011), Revista Brasileira de Ciência Política (2010), Pro-posições (2009), Cadernos Ceru (2009).
} 
A identidade tem sido um conceito há muito utilizado pela filosofia e pelas ciências humanas. A partir da segunda metade do século 20, sua presença na sociologia e na psicologia tem sido mais intensa. $\mathrm{O}$ seu desenvolvimento nas teorias dos movimentos sociais e nos estudos dos processos de engajamento remete às teorias dos novos movimentos sociais, desenvolvidas sobretudo na Europa desde a década de 1980 (Polleta e Jasper, 2001). Mais recentemente, a partir de sua incorporação pelo conjunto das perspectivas teóricas dos movimentos sociais, o conceito de identidade tem sido apontado como instrumento analítico fértil para a compreensão dos processos subjetivos relacionados à ação coletiva.

De forma geral, as teorias dos movimentos sociais têm abordado a identidade como um fenômeno coletivo. No entanto, a literatura atual sobre identidade produzida pela sociologia e pela psicologia tem enfatizado o caráter múltiplo da identidade, destacando os processos de interação entre a identidade coletiva e a identidade individual (Thoits e Virshup, 1997; Brewer, 2001; Owens et al., 2010). Nos estudos sobre engajamento, essa multidimensionalidade é percebida através da constatação do dinamismo, da contingência e da multiplicidade das interações sociais, o que traz como implicação que "não é apenas o atributo ou a posição social que determina a identidade, mas também são as experiências e orientações coletivas dentro de um dado contexto concreto que criam o potencial para formas diferenciadas de reconhecimento" (Mische, 1997, p. 139). Justamente, tendo esta muldimensionalidade dos processos identitários por referência, propõe-se neste artigo que a compreensão da relação entre a identidade coletiva (produzida pelos movimentos sociais) e a identidade individual demanda uma análise aprofundada das dimensões pessoal, social e coletiva da identidade individual, destacando-se não apenas seus elementos e características específicas, mas as interdependências entre essas dimensões e suas relações com os processos coletivos que produzem e dão sustentação à identidade coletiva dos movimentos sociais.

Assim, este artigo propõe um modelo teórico para analisar como, no processo de formação da identidade militante, ${ }^{2}$ participam as múltiplas dimensões do fenômeno identitário individual (pessoal, social e coletiva) e como essas dimensões se conectam à identidade coletiva dos movimentos sociais.

\footnotetext{
${ }^{2} \mathrm{Na}$ medida em que objetiva a construção de um modelo analítico, a argumentação desenvolvida neste artigo não pretende apresentar uma revisão exaustiva da literatura sobre o tema, mas sim mobilizar argumentos presentes nesta literatura para a elaboração daquele modelo. Além do diálogo com a literatura, o modelo de análise proposto também tem por base a pesquisa empírica com militantes do Movimento de Saúde do Trabalhador, de Naujorks (2011), cujos resultados, pelos limites do artigo, não puderam ser incorporados na argumentação.
} 


\section{Identidade como processo de identificação e categorização}

Pode-se entender a identidade como um conjunto de processos cognitivos e afetivos, de construção e atribuição de significados que pessoas, individual e coletivamente, elaboram sobre si mesmas, outras pessoas, grupos e a sociedade, a partir de referências pessoal e socialmente construídas. ${ }^{3}$ Essa definição destaca, pelo menos, quatro características dos processos identitários: 1) a identidade é produzida a partir das relações sociais; 2) essa produção envolve processos cognitivos e afetivos; 3) ela envolve tanto indivíduos quanto coletividades; e, ainda, 4) implica em processos de reconhecimento e diferenciação social.

Toda identidade é social no sentido de que é decorrente das relações sociais e dos grupos sociais em que cada pessoa participa (Jenkins, 1996). Essa noção afasta duas características tradicionalmente associadas à identidade: seu caráter essencial, pelo qual a identidade se referiria a algo intrínseco a determinado ser; sua atemporalidade, em que a identidade se referiria a algo contínuo e imutável desse ser. Compreender o fenômeno identitário como uma construção social é, justamente, enfatizar suas dimensões social e histórica. A identidade é uma construção social de significados, sentimentos e emoções associados ao autorreconhecimento e ao reconhecimento dos outros. Essa construção é tanto singular (própria a um indivíduo particular) quanto coletiva (própria a um conjunto de indivíduos). Enquanto construção singular, os significados e sentimentos são apreendidos cognitivamente e vivenciados emocionalmente.

Enquanto processo cognitivo de apreensão de si, a identidade é produzida por atividades contínuas de identificação e categorização (Jenkins, 1996). Identidade e identificação referem-se, assim, a dois aspectos de um mesmo fenômeno, sendo a identificação o mecanismo que confere um caráter processual à identidade. $\mathrm{O}$ sujeito produz sua identidade pelas identificações com determinados objetos, que se tornam referentes para processos de categorização. Tal entendimento do processo identitário, que orienta a argumentação deste artigo, pode ser sintetizado no esquema 1, a seguir.

\footnotetext{
${ }^{3}$ Há uma tensão presente em várias teorias da identidade entre o sentido objetivado/reificado que é dado pelo substantivo "identidade" e a "identificação" como um processo dinâmico e múltiplo. Esta dualidade decorre do caráter ao mesmo tempo objetivo e subjetivo da identidade, que pelos limites deste trabalho, não será aqui desenvolvido.
} 
Esquema 1. O processo identitário

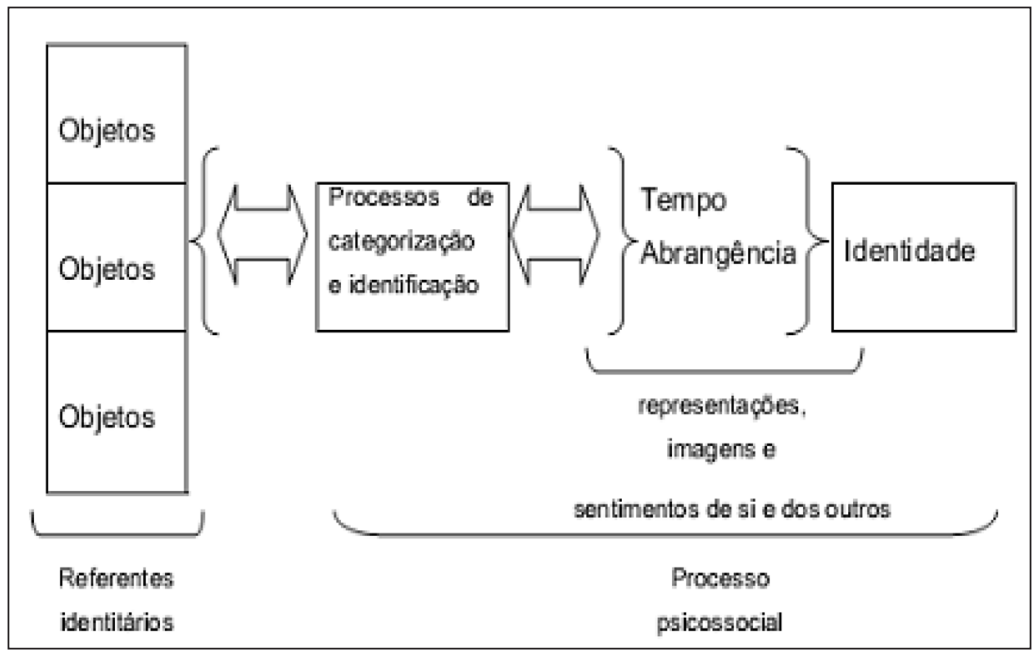

Fonte: Naujorks (2011).

Numa perspectiva cognitivista, a categorização refere-se a um processo de tratamento de informações pela percepção (Tajfel, 1982). A realidade social pode ser percebida pelas diferenças entre as pessoas, objetos, eventos e processos sociais. A categorização é um instrumento para os indivíduos construírem "um sistema coerente de orientação no ambiente social" (Tajfel, 1982, p. 59). Assim, a categorização refere-se a "processos psicológicos que tendem a organizar o entorno em termo de categorias: grupos de pessoas, de objetos, de eventos (ou grupos de alguns de seus atributos) enquanto são semelhantes ou equivalentes uns aos outros para a ação, as intenções ou atitudes de um sujeito" (Tajfel citado por Deschamps e Moliner, 2009, p. 28). Sua função é, então, sistematizar, diferenciar e organizar o entorno.

A categorização é produzida pelos sujeitos em relação aos objetos. Dessa forma, a categorização envolve tanto suas intenções quanto os valores, normas e orientações culturais que compartilha. O indivíduo define os caracteres comuns a determinados objetos para produzir a categorização e faz isso a partir das relações sociais e da cultura em que vive. Porém, os indivíduos não produzem isoladamente seus esquemas de categorização, mas sim utilizam as (e, ao mesmo tempo, situam-se nas) categorias definidas por outros indivíduos e pela sociedade (Deschamps e Moliner, 2009). 
As categorias são utilizadas como referentes para a produção da identidade. Os referentes constituem para o sujeito as vivências e percepções do $e u$. Os referentes identitários são múltiplos e diversos já que pode se constituir como referente tudo aquilo que possa ser feito significativo para um sujeito. Esses referentes são situações, fatos ou acontecimentos, objetos reais ou imaginários, significados sociais e/ou culturais, ideias, valores, normas, pessoas etc. que aparecem como objeto reflexivo para o sujeito construir uma imagem e um sentimento de si e dos outros (Mucchielli, 1994). $\mathrm{O}$ sujeito toma como referente ${ }^{4}$ para sua construção identitária individual objetos que dizem respeito a si e sua história (identidade pessoal), às categorias sociais de que participa (identidade social) e aos seus pertencimentos grupais (identidade coletiva). Assim, a diferenciação da identidade individual em dimensões (pessoal, social e coletiva) decorre de uma diferenciação (analítica) dos referentes que servem de base para os processos de identificação.

\section{A dimensão pessoal da identidade individual}

A identidade pessoal envolve a autodescrição que o indivíduo realiza sobre si como uma pessoa única e os sentimentos associados ao reconhecimento pessoal (Owens et al., 2010). Esse conhecimento produzido sobre si é mediado pelo sistema cultural em que o indivíduo está inserido, por quadros interpretativos próprios aos grupos de que faz parte e pelos processos de formação da personalidade (Mucchielli, 1994). As experiências afetivas produzidas ao longo da existência de cada um intervêm na percepção do mundo e nas relações entre esses indivíduos e os outros (indivíduos, grupos e coletividades).

Para teorias interacionistas, a identidade pessoal está relacionada aos processos de construção e manutenção do Self e têm com como base os significados construídos e compartilhados na interação social. Para o interacionismo, o Self é um fenômeno decorrente da reflexividade humana, sendo produzido pelos processos de interação quando, na relação com o outro, o indivíduo percebe-se e coloca a si-mesmo como objeto. Deriva daí a noção de objeto do Self ou, na perspectiva de George Herbert Mead (1992 [1934]), o ' $M e$ ', o Eu-objeto, o Self tomado enquanto objeto. Ao colocar-se como objeto, o indivíduo percebe a si-mesmo como alguém que realiza a reflexão e daí a percepção do si-mesmo como sujeito ou, novamente nos termos de Mead,

\footnotetext{
${ }^{4}$ Todos os referentes são organizados pelos processos de categorização, mas nem todos são utilizados nos processos de identificação.
} 
aparece o ' $I$ ', o Eu-sujeito, o Eu que realiza a reflexão e que se percebe como autor dessa reflexão.

Com a emergência do Self, emerge, concomitante, um autoconceito (self-concept), uma representação identitária que o Self elabora tendo por referência seu polo objeto (o ' $M e$ '). $\mathrm{O}$ autoconceito pode ser definido como "a totalidade dos pensamentos e sentimentos de uma pessoa acerca de simesma ou tomando a si-mesma como um objeto de reflexão" (Rosemberg, citado por Owens et al., 2010, p. 479). Autoconceito envolve, então, o conjunto dos nossos pensamentos, sentimentos e imaginações sobre quem nós somos e de como os outros nos veem (Stets e Burke, 2000). O autoconceito é a base para a identidade pessoal e um dos seus componentes é a autoestima (selfesteem), o valor que a pessoa atribui a si mesma. Emoções positivas (sentir-se íntegro, bem e feliz) decorrem da congruência entre autoestima e autoconceito. A inexistência ou a sucessiva interrupção dessa congruência relaciona-se com emoções de incoerência e desapreço pessoal (Stets, 2005).

A identidade pessoal tomada como um senso de si construído ao longo do tempo envolve a pessoa e seus projetos como derivados dela mesma e não de algo que the seja colocado pela sociedade. Dessa forma, a identidade pessoal envolve um senso de sentir-se único, de ser exclusivo (Hitlin, 2003).

A identidade pessoal é produzida a partir de fatos e situações que são vivenciadas pelo indivíduo como únicas e que permitem ao individuo conformar uma narrativa pessoal sobre si (Owens et al., 2010). Dessa forma, a identidade pessoal pode ser evidenciada pelas autodescrições realizadas pela pessoa que têm como referência os detalhes únicos e específicos relacionados à sua biografia e ao caráter idiossincrático de suas experiências.

\section{A dimensão social da identidade individual}

A identidade individual é composta não apenas pelas identificações estritamente idiossincráticas e biográficas. Identificações vinculadas às e mantidas pelas relações sociais também compõem a identidade individual. A essa dimensão da identidade tem-se denominado de identidade social (Thoits e Virshup, 1997; Sedikides e Brewer, 2001).

A noção de identidade social tem sido utilizada pelas teorias da identidade em pelo menos três sentidos diferentes. Num primeiro e mais amplo, na perspectiva de que toda identidade é social. A afirmação de que toda identidade é social, já referida anteriormente, relaciona-se com a contraposição a uma perspectiva naturalista e substancialista da identidade, afirmando o caráter social e processual de sua produção. Nesse sentido, inclusive a identidade pessoal é social. Uma segunda perspectiva evidencia os 
aspectos de pertencimento social que estão presentes na identidade individual. Faz-se uma diferenciação entre os aspectos eminentemente pessoais, de caráter idiossincrático e biográficos da identidade pessoal, e aqueles que constituem a identidade individual mantidos pelas relações sociais (Brewer, 2001). Uma terceira perspectiva toma a identidade social como a identidade do indivíduo em relação a uma categoria ou coletividade social, o que implica no reconhecimento dos membros dessa categoria como seus constituintes.

Considerando-se as duas últimas perspectivas, pode-se definir a identidade social como "as maneiras pelas quais indivíduos e coletividades são diferenciados, a partir de suas relações sociais, de outros indivíduos ou coletividades" (Jenkins, 1996, p. 4). Dessa forma, identidade social implica em processos de diferenciação e categorização social. Esses processos de diferenciação podem ter como fundamento a localização do indivíduo na sociedade pelo desempenho de determinados papéis sociais ou o pertencimento do indivíduo a determinadas posições ou categorias sociais.

Sheldon Stryker compreende a identidade social ${ }^{5}$ como um esquema cognitivo produzido pelos significados que as pessoas atribuem a si mesmo tendo como referência o desempenho de papéis sociais e suas posições sociais (Thoits e Virshup, 1997; Stryker, 1981; Stryker, 2000). Enquanto elaborações cognitivas, as identidades variam e são organizadas hierarquicamente. Esta organização hierárquica é denominada de saliência identitária, a qual é definida como a probabilidade de uma identidade aparecer em jogo em uma variedade de situações. Saliência identitária evidencia a disposição para a pessoa expressar uma identidade em detrimento de outras como uma decorrência de suas propriedades como um esquema cognitivo (Stryker, 2000). Além disso, a força e a intensidade das emoções estão relacionadas com a saliência de uma determinada identidade (Stets, 2005). A saliência identitária constitui-se como uma parte estável do Self, algo que a pessoa carrega consigo em diferentes situações (Owens et al., 2010). Com o conceito de saliência identitária, Stryker propõe uma perspectiva transsituacional de identidade (Stryker, 2000), articulando-se esse conceito com uma outra noção, a de processo identitário. A noção de processo identitário permite relacionar a dimensão pessoal e a dimensão social da identidade. Processo identitário refere-se, então, às ações que criam, apresentam e mantêm as diversas dimensões identitárias congruentes e sustentadas pelo autoconceito (Snow e McAdam, 2000). Os processos identitários envolvem, então, as ações realizadas pelas pessoas

\footnotetext{
${ }_{5}^{5}$ Stryker utiliza a denominação identidade, simplesmente, para o que aqui estamos denominando identidade social.
} 
para dar significado para si próprio ou para outros, através da produção de uma congruência entre suas diversas identidades possíveis (Snow e McAdam, 2000). Essa congruência permite, também, sentimentos e emoções positivas acerca de si e dos outros (Stets, 2006).

De forma geral, as identidades sociais referem-se à identidade de gênero, de etnia, de profissão, entre outras, na medida em que permitem o reconhecimento de um indivíduo pela sua pertença a determinadas categorias e, ao mesmo tempo, o sentimento de pertencimento desse indivíduo em relação a essas categorias.

\section{A dimensão coletiva da identidade individual}

A noção de identidade coletiva está diretamente associada à literatura sobre movimentos sociais, tendo sido esse conceito amplamente utilizado para análise do que se convencionou chamar de novos movimentos sociais (Habermas, 1981; Touraine, 1985, 2000; Melucci, 1985, 1996, 2001; Cohen, 1985; Hunt e Benford, 2004) e de movimentos identitários (Calhon, 1994; Polletta e Jasper, 2001). A literatura sociológica contemporânea sobre identidade coletiva tem destacado os processos de solidariedade que são constituídos na medida em que as pessoas, ao se perceberem compartilhando uma mesma identidade, percebem-se também como vivenciando uma mesma realidade e tendo como comuns comportamentos, emoções e o uma determinada perspectiva de destino (Owens et al., 2010, p. 490).

Um sentido que tem sido dado pela literatura psicológica contemporânea para a noção de identidade coletiva é o de identificação com um coletivo (Klandermans, 1984, 1997, 2004; Klandermans e Oegema, 1987; Klandermans e De Weerd, 2000; Simon e Klandermans, 2001). Para Bernd Simon e Bert Klandermans (2001), a identidade coletiva assume o sentido específico da identidade de uma pessoa como membro de um grupo. A identidade é coletiva porque a pessoa compartilha a fonte de sua identidade (o fazer parte de um determinado grupo) com outras pessoas. Aqui, a identidade coletiva se refere a uma identidade mais inclusiva que a identidade social. A identidade coletiva dá o sentido do "nós" através do sentimento de pertencimento individual a um determinado grupo social (Simon e Klandermans, 2001, p. 321). Para Marilynn Brewer (2001), a identidade coletiva refere-se a uma identidade que é vivenciada pelo indivíduo como fonte de um sentimento de pertencimento a um "nós".

Assim, a identidade coletiva constitui-se, sobretudo, pelo pertencimento: o sentir-se parte e integrar um determinado coletivo. Timothy Owens, Dawn Robinson e Lynn Smith-Levin (2010) sugerem, nesse sentido, que a identidade coletiva deva ser vista como uma dinâmica dos processos identitários no âmbito 
grupal, uma dinâmica que envolve uma identificação individual com um grupo pela percepção e sentimento de pertença a esse grupo e uma construção pelo grupo das identificações que permitem a cada um a produção das identificações individuais.

É próximo a esse sentido que Alberto Melucci (1996, p. 70) define identidade coletiva como "uma definição compartilhada, produzida por um número de indivíduos (ou grupos em um nível mais complexo), sobre as orientações de suas ações e o campo de oportunidades e constrangimentos no qual suas ações acontecem". Para essa perspectiva, a identidade coletiva é um fenômeno que acontece no nível grupal, sendo central para dar ao grupo a coerência e a energia necessárias para mobilizar seus constituintes na ação coletiva.

A identidade coletiva envolve uma definição sobre os fins, os significados e o campo de ação que são interpretados coletivamente a partir de referentes culturais amplos. Tais referentes são enquadrados pelos indivíduos a partir dos grupos em que estão envolvidos. A identidade coletiva constitui-se, então, através de uma rede de interações entre atores que se comunicam, influenciamse mutuamente, negociam e tomam decisões. Esse processo constitui para o indivíduo um sentimento de constituir uma unidade comum (Melucci, 1996).

\section{O processo de correspondência identitária}

David Snow e Doug McAdam (2000), em uma análise da relação entre a identidade individual e a identidade coletiva, desenvolvem a noção de correspondência identitária. Para os autores, a correspondência identitária refere-se aos processos de alinhamento da identidade do indivíduo com a identidade coletiva do grupo no qual participa. A correspondência identitária acontece tendo como base processos de congruência entre a identidade individual e a identidade coletiva.

Para Snow e McAdam, os processos que possibilitam a congruência entre a identidade individual e a identidade coletiva acontecem tendo como pano de fundo a criação e manutenção de quadros interpretativos. Isso ocorre através das interações e comunicações entre as pessoas, na medida em que divulgam os valores, normas, significados e sentidos trazidos pelo grupo ou movimento, falam sobre ele, preparam material de divulgação etc. Em contextos de interação, as identidades são anunciadas e reanunciadas, sendo meio para isto os esquemas comunicativos.

O conceito de correspondência identitária apresentado por Snow e McAdam é utilizado neste artigo para a compreensão dos processos que tornam convergentes as múltiplas dimensões da identidade individual. Da mesma forma que os autores salientam a necessidade de congruência entre a 
identidade individual e a identidade coletiva para que ocorra o envolvimento dos indivíduos na ação coletiva, defende-se aqui que as dimensões pessoal, social e coletiva que conformam a identidade individual também precisam convergir para que se observe o engajamento. $\mathrm{O}$ argumento central deste artigo, então, é de que o engajamento relaciona-se não apenas com a convergência entre a identidade individual e a identidade coletiva, mas, e fundamentalmente, com a produção de correspondência entre as múltiplas dimensões no interior da identidade individual. Ou seja, sustenta-se que os processos de correspondência entre a identidade individual e a identidade coletiva precisam ser acompanhados, em alguma medida, de processos de correspondência entre as dimensões que compõe a identidade individual: as dimensões pessoal, social e coletiva da identidade individual.

Aqui, o conceito de quadros interpretativos pode ser operacionalmente útil. O conceito de quadros interpretativos destaca a importância dos significados socialmente compartilhados para a definição do campo social e das possibilidades de ação. Quadros interpretativos são entendidos, de forma ampla, como "os significados e definições compartilhadas por meio dos quais as pessoas definem sua situação" (McAdam et al., 1996, p. 5). O conceito de quadros interpretativos parte do conceito de frame, tal qual desenvolvido por Erving Goffman. Goffman (1986, p. 247) define framing como o processo pelo qual os indivíduos organizam suas experiências, dando um sentido a elas e criando as possibilidades de agir socialmente. Esse processo é, ao mesmo tempo, psicológico e social. A incorporação do conceito de frame às teorias dos movimentos sociais está relacionada com uma crescente preocupação com os processos microssociais presentes nos movimentos sociais, para além daqueles aspectos estruturais e organizacionais (Snow et al., 1986). Fundamentalmente, essa incorporação tem procurado elucidar questões referentes ao engajamento e à participação das pessoas nos movimentos sociais.

Dessa forma, quadros interpretativos são entendidos como esquemas de interpretação que tornam as pessoas capazes de localizar, perceber, identificar e rotular ocorrências dentro de seus mundos e espaços de vida, servindo para orientar a ação (Snow et al., 1986).

Os processos de correspondência identitária ao nível individual, ou seja, a relação entre as dimensões pessoal, social e coletiva da identidade individual, pressupõe uma congruência entre os significados presentes em cada uma dessas dimensões identitárias que dispõe ao engajamento. Ou seja, uma congruência entre as estruturas de significado que compõe cada dimensão identitária.

Pressupõe-se, assim, que na identidade militante haverá não apenas uma congruência entre os significados e sentidos que conformam os quadros 
interpretativos do individuo e do movimento social, mas também uma correspondência entre os referentes presentes nas diversas dimensões identitárias do indivíduo. Da mesma forma que o marco interpretativo apresentado pelo movimento social deve, em certa medida, ser congruente com os esquemas interpretativos utilizados pelo sujeito, as estruturas de significado em relação às quais adquirem sentido os referentes de cada dimensão da identidade individual (pessoal, social e coletiva) devem ser, também, congruentes entre si. A correspondência identitária entre essas dimensões, a partir dos processos de saliência, alinhamento e convergência identitária, é o mecanismo através do qual se produz o autorreconhecimento identitário.

Para esse processo, a noção de alinhamentos de quadros interpretativos (frame alignment) (Snow et al., 1986) torna-se fundamental. Alinhamentos de quadros interpretativos são entendidos como a conexão entre as orientações interpretativas dos indivíduos e interpretações produzidas pelas organizações dos movimentos sociais. Através do alinhamento, interesses, valores e crenças individuais tornam-se congruentes em relação aos apresentados pelas organizações dos movimentos sociais e em relação às atividades que essas organizações desenvolvem. A função dos alinhamentos interpretativos é de organizar a experiência e orientar a ação dos indivíduos, sendo uma condição necessária para a participação nos movimentos sociais (Snow et al., 1986).

O modelo analítico proposto para analisar a correspondência identitária que hipoteticamente fundamenta os processos de engajamento individual pode, então, ser sintetizado no esquema 2, a seguir.

Esquema 2. Modelo relacional da identidade individual militante

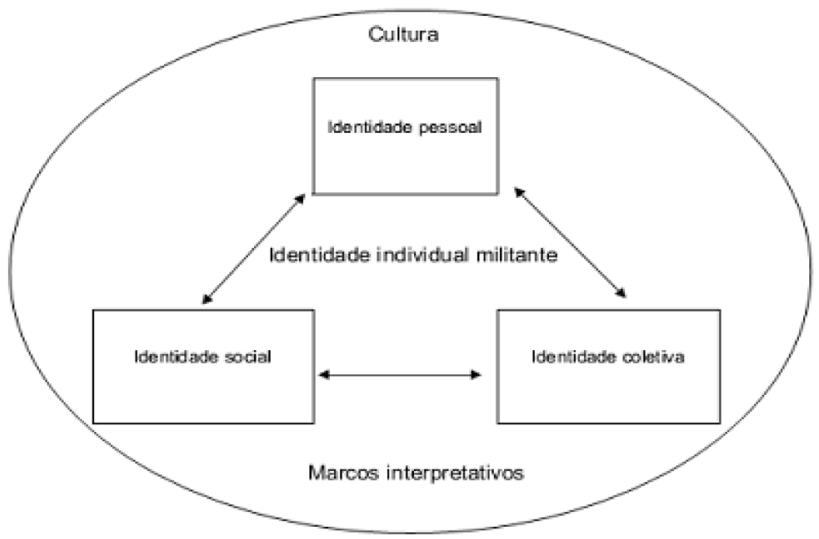

Fonte: Naujorks (2011). 


\section{Considerações finais}

A identidade militante é um fenômeno coletivo na medida em que se relaciona com os processos coletivos de pertencimento e as possibilidades da ação coletiva. A identidade militante é, também, um fenômeno individual, pois pressupõe que o pertencimento a coletividades deve se tornar um referente a ser individualmente apropriado. Assim, enquanto fenômeno singular, a identidade militante é produzida pelo autorreconhecimento realizado pelo indivíduo. No âmbito individual, esse autorreconhecimento pressupõe tanto a identificação de pertencimento a coletividades, quanto a identificação com referentes pessoais e sociais que dão significado e justificam o engajamento. Dessa forma, o autorreconhecimento identitário militante é constituído pelas correspondências produzidas entre as três dimensões da identidade individual: a identidade coletiva, a identidade social e a identidade pessoal. Como decorrência, as relações de correspondência estabelecidas entre esses referentes podem estar associadas às distintas formas, variações e graus de engajamento.

A identidade militante tem na correspondência identitária o mecanismo que a produz e nos quadros interpretativos o conteúdo que a preenche e dá significado. No âmbito do indivíduo, a singularidade da experiência militante é produzida pela configuração particular da correspondência entre as diferentes dimensões identitárias e pela particularidade dos conteúdos veiculados pelos quadros interpretativos.

O modelo analítico apresentado salienta, assim, a centralidade dos processos de correspondência identitária para a produção da identidade militante. Isso implica que a incorporação dos processos identitários nas teorias dos movimentos sociais deve rejeitar a redução deste conceito a um tipo específico de movimento social (os novos movimentos sociais ou, ainda, os movimentos identitários) e incorporá-la como um mecanismo constitutivo dos processos de engajamento em geral. Nesse caso, a identidade constituiria mais um mecanismo psicossocial que operaria na base dos processos de engajamento e não um critério para uma tipologia de movimentos sociais (Gohn, 2008).

A análise dos processos de correspondência identitária também poderia ser útil para os estudos que tematizam, de alguma forma, a questão da diversidade de formas e intensidades de engajamento. Há, no conjunto da literatura recente sobre engajamento, o forte desenvolvimento de uma perspectiva teórica que destaca o papel dos elementos estruturais e relacionais que dispõem ao engajamento (Fillieule, 2001, 2005; Agrikoliansky, 2001). De forma geral, 
para esta perspectiva, a variação do engajamento relaciona-se com variações nas relações entre esses elementos. Assim, alguns estudos têm compreendido as diferenciações do engajamento a partir da importância das trajetórias e carreiras dos agentes (Agrikoliansky, 2001), das disposições favoráveis ao engajamento (Reis, 2007; Seidl, 2009), do capital social e da posição relativa dos agentes (Coradini, 2007), da influência da inserção diferenciada nas redes sociais (Passy, 1998, 2000; Passy e Giugni, 2001). Assim, para além das dimensões estrutural e relacional dos processos de engajamento, o modelo proposto pode contribuir para os processos psicossociais de atribuição de sentido que mobilizam e sustentam o engajamento do indivíduo.

A partir das considerações feitas, podemos dizer que o modelo de análise do reconhecimento identitário a partir dos processos de correspondência identitária aqui apresentado pode contribuir com as análises dos diferentes padrões de engajamento para um movimento social em particular, bem como a comparação entre os padrões de engajamento entre diferentes movimentos. $\mathrm{O}$ engajamento relacionado a um autorreconhecimento identitário que se produz a partir das correspondências entre as múltiplas dimensões da identidade individual poderia contribuir na compreensão das variações (de modalidade e intensidade) desse engajamento. Além disso, o modelo torna possível também perceber as variações no engajamento e no autorreconhecimento identitário ao longo do tempo em relação a um movimento particular.

\section{Referências}

AGRIKOLIANSKY, Éric. Carrières militantes et vocation à la morale: les militants de la LDH das les années 1980. Revue Francaise de Science Politique, v. 15, n. 1-2, p. 27-46, 2001.

BREWER, Marilynn B. The Many faces of social identity: implications for political psychology. Political Psychology, v. 22, n. 1, p. 115-125, 2001.

CALHOUN, Graig. Social theory and the politics of identity. Malden (Massachusetts): Blackwell Publishing, 1994.

COHEN, Jean. Strategy or identity: new theoretical paradigms and contemporary social movements. Social Research, v. 52, n. 4, p. 663-716, 1985.

CORADINI, Odaci Luiz. Engajamento e militância para os participantes e promotores do Fórum Social Mundial. Porto Alegre: 7ạ Reunião de Antropologia do Mercosul, 2007. GT 2.

DESCHAMPS, Jean-Claude; MOLINER, Pascal. A identidade em psicologia social: dos processos identitários às representações sociais. Petrópolis: Vozes, 2009.

FILLIEULE, Olivier. Propositions pour une analyse processuelle de l'engagement individuel. Revue Francaise de Science Politique, v. 51, n. 1-2, p. 199-215, 2001. 
FILLIEULE, Olivier. Le désengagement militant. Paris: Belin, 2005.

GAXIE, Daniel. Rétributions du militantisme et paradoxes de 1'action collective. Swiss Political Science Review, v. 11, n. 1, p. 157-188, 2005.

GOFFMAN, Erving. Frame analysis: an essay on the organization of experience. Boston: Northeastern University Press, 1986.

GOHN, Maria da Glória. O protagonismo da sociedade civil: movimentos sociais, ONGs e redes solidárias. 2. ed. São Paulo: Cortez, 2008.

HABERMAS, Jürgen. New social movements. Telos, v. 49, p. 33-37, 1981.

HITLIN, Steven. Values as the core of personal identity: drawing links between two theories of Self. Social Psychology Quarterly, v. 66, n. 2, p. 118-137, 2003.

HUNT, Scott A.; BENFORD, Robert. Collective identity, solidarity and commitment. In: David A. Snow; Sarah A. Soule; Hanspeter Kriesi (orgs.). The Blackwell companion to social movements. Oxford: Blackwell, 2004. p. 433-457.

JENKINS, Richard. Social identity. New York: Routledge, 1996.

KLANDERMANS, Bert. Mobilization and participation: social-psychological expansions of resource mobilization theory. American Sociological Review, v. 49, p. 583-600, 1984.

KLANDERMANS, Bert. The social psychology of protest. Oxford: Blackwell Publisher, 1997.

KLANDERMANS, Bert. The demand and supply of participation: social-psychological correlates of participation in social movements. In: David A. Snow; Sarah A. Soule; Hanspeter Kriesi (orgs.). The Blackwell companion to social movements. Oxford: Blackwell, 2004. p. 360-379.

KLANDERMANS, Bert; OEGEMA, Dirk. Potentials, networks, motivations, and barriers: steps towards participation in social movements. American Sociological Review, v. 52, n. 4, p. 519-531, 1987.

KLANDERMANS, Bert; DE WEERD, Marga. Group identification and political protest. In: Sheldon Stryker; Timothy Owens; Robert White. Self, identity, and social movements. Minnesota: University of Minnesota Press, 2000. p. 68-90.

McADAM, Doug; McCARTHY, John D.; ZALD, Mayer N. Introduction: opportunities, mobilizing structures and framing process - toward a synthetic, comparative perspective on social movements. In: Doug McAdam; John D. McCarthy; Mayer N. Zald (orgs.). Comparative perspectives on social movements. political opportunities, mobilizing structures and cultural framings. Cambridge: Cambridge University Press, 1996.

MEAD, George Herbert. Mind, self \& society from a standpoint of a social behaviorist. Chicago: The University of Chicago Press. 1992 [1934].

MELUCCI, Alberto. The symbolic challenge of contemporary movements. Social Research, v. 52, n. 4, p. 789-816, 1985.

MELUCCI, Alberto. Challenging codes: collective action in the information age. Cambridge: University Press, 1996. 
MELUCCI, Alberto. A invenção do presente: movimentos sociais nas sociedades complexas. Petrópolis: Vozes, 2001.

MISCHE, Ann. De estudantes a cidadãos: redes de jovens e participação política. Revista Brasileira de Educação, n. 5-6, p. 134-150, 1997.

MUCCHIELLI, Alex. L'identité. 3. ed. Paris: Press Universitaire de France, 1994.

NAUJORKS, Carlos José. Processo identitário e engajamento: um estudo a partir do Movimento de Saúde do Trabalhador no Rio Grande do Sul. Tese (Doutorado) - PPG em Sociologia, Universidade Federal do Rio Grande do Sul, Porto Alegre, 2011.

OWENS Timothy J.; ROBINSON Dawn T.; SMITH-LOVIN. Lynn. Three faces of identity. Annual Review of Sociology, v. 36, p. 477-499, 2010.

PASSY, Florence. L'action altruiste: contraintes et opportunités de 1'engagement dans les mouvements sociaux. Genève: Librairie Dorz, 1998.

PASSY, Florence; GIUGNI, Marco. Life-spheres, networks, and sustained participation in social moviments: a phenomenological approach to political commitment. Sociological Forum, v. 15, n. 1, p. 117-144, 2000.

PASSY, Florence; GIUGNI, Marco. Social networks and individual perceptions: explaining differential participation in social movements. Sociological Forum, v. 16, n. 1, p. 123-153, 2001.

POLLETTA, Francesca; JASPER, James M. Collective identity and social movements. Annual Review of Sociology, v. 27, p. 283-305, 2001.

REIS, Eliana Tavares dos. Contestação, engajamento e militantismo: da "luta contra a ditadura" à diversificação das modalidades de intervenção política no Rio Grande do Sul. Tese (Doutorado) - Programa de Ciência Política da Universidade Federal do Rio Grande do Sul, 2007.

SAWICKI, Frédéric; SIMÉANT, Johanna. Inventário da sociologia do engajamento militante: nota crítica sobre algumas tendências recentes dos trabalhos franceses. Sociologias, v. 13, n. 28, p. 200-255, 2011.

SEDIKIDES, Constantine; BREWER, Marilynn B. Individual self, relational self, and collective self: partners, opponents or strangers? In: Constantine Sedikides; Marilynn B. Brewer (orgs.). Individual self, relational self, and collective self. Philadelphia: Psychology Press, 2001. p. 1-4.

SEIDL, Ernesto. Disposições a militar e lógica de investimentos militantes. Proposições, v. 20, n. 2, p. 21-39, 2009.

SIMON, Bernd; KLANDERMANS, Bert. Politicized collective identity: a social psychological analysis. American Psychologist, v. 56, n. 4, p. 319-331, 2001.

SNOW, David; ROCHFORD, E. Burke; WORDEN, Steven K.; BENFORD, Robert. Frame aligment processes, micromobilization and movement participation. American Sociological Review, v. 51, p. 464-481, 1986.

SNOW, David; McADAM, Doug. Identity work processes in the context of social movements: clarifying the identity/movement nexus. In: Sheldon Stryker; Timothy Owens; Robert White. Self, identity, and social movements. Minnesota: University of Minnesota Press, 2000. p. 41-67. 
STETS, Jan E.; BURKE, Peter J. Identity theory and social identity theory. Social Psychology Quarterly, v. 63, n. 3, p. 224-237, 2000.

STETS, Jan E. Examining emotions in identity theory. Social Psychological Quarterly, v. 68, n. 1, p. $39-74.2005$.

STETS, Jan E. Identity theory and emotions. In: Jan E. Stets; Jonatham H. Turner. Handbook of socioloy of emotions. New York: Springer, 2006. p. 203-223.

STRYKER, Sheldon. Social psychology: trends, assessment and prognosis. American Behavioral Scientist, v. 24, n. 3, p. 386-406, 1981.

STRYKER, Sheldon. Identity competition: key to differential social movement participation. In: Sheldon Stryker; Timothy Owens; Robert White. Self, identity, and social movements. Minnesota: University of Minnesota Press, 2000. p. 21-40.

TAJFEL, Henri. Grupos humanos e categorias sociais: estudos em psicologia social. v. 1 e 2. Lisboa: Livros Horizonte, 1982.

TOURAINE, Alain. An introduction to the study of social movements. Social Research. v. 52, n. 4, p. 750-787, 1985.

TOURAINE, Alain. Sociologie de l'action: essai sur la société industrielle. Paris: Seuil, 2000.

THOITS, Peggy A.; VIRSHUP, Lauren K. Me's and We's: forms and functions of social identities. In: Richard D. Ashmore; Lee Jussim (orgs.). Self and identity: fundamental issues. New York: Oxford University Press, 1997. p. 106-133.

Recebido em: 24 jul. 2014

Aprovado em: 15 dez. 2015

Autor correspondente

Carlos José Naujorks

Universidade Federal de Santa Catarina

Departamento de Psicologia

Campus Universitário - Trindade

88040-970 Florianópolis, SC, Brasil 